\title{
Duodenal Metastases of Malignant Melanoma: One Case Report
}

\author{
Soro Dramane 1*, Ouattara Amadou1, Okon Anassi Jean Baptiste², Koné Siaka1, \\ Assi Constant', Allah-Kouadio Emile', N'dah K. Justin ${ }^{3}$, Ndjitoyap Ndam Antonin Wilson', \\ Diallo Djeinabou', Lohoues-Kouacou Marie Jeanne d'Arc'1, Camara Benoît Mathieu ${ }^{1}$ \\ ${ }^{1}$ Service d'Hépato-Gastroentérologie, CHU Cocody, Abidjan, Côte d'Ivoire \\ ${ }^{2}$ Service d'Hépato-Gastroentérologie, CHU Bouaké, Bouaké, Côte d'Ivoire \\ ${ }^{3}$ Service d'Anatomie Pathologique, CHU Cocody, Abidjan, Côte d'Ivoire \\ Email: ${ }^{*}$ drambake@yahoo.fr, ${ }^{*}$ drambake@hotmail.com
}

Received 2 July 2015; accepted 10 August 2015; published 13 August 2015

Copyright (C) 2015 by authors and Scientific Research Publishing Inc.

This work is licensed under the Creative Commons Attribution International License (CC BY).

http://creativecommons.org/licenses/by/4.0/

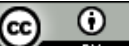

Open Access

\section{Abstract}

The duodenal metastases of a malignant melanoma are rare. We report a case at a 86-year-old, hypertense patient, without tumoral history, who was hospitalized in our department for a change of the general state and an anaemia ferriprive without found home (foyer) of display. In the clinical examination, we had found anemia syndrome, nodules under cutaneous about $2 \mathrm{~cm}$ in diameter at the level of the thorax, of the belly, the members and of the lower lip partners in a painless left adenopathy axillary about $3 \mathrm{~cm}$ in diameter and an absence of méléna in the rectal touch. The gastroscopy had highlighted polypoïdes ulcéro-bourgeonnantes hurts with a blackish pigmentation by places at the level of the bulb and of the second duodenum. In the histology of biopsie fragments, we noted a fuso-cellular proliferation and epithelioid with deposits of melanin. The positivity of antibodies anti-protein $\mathrm{S100}$ and anti HMB45 in the immunohistochemical study allowed confirming the diagnosis. The gastroduodenal hurts, persons suffering from a liver complaint and lungworts in the scanner testify of a terminal metastatic scattering. The death arose two months later, in a picture of circulatory collapse further to a high digestive bleeding of big abundance.

\section{Keywords}

Duodenal Metastases, Malignant Melanoma

\section{Introduction}

Malignant melanoma is a rare tumor; it primarily affects the skin and mucous membranes. This tumor is charac-

${ }^{*}$ Corresponding author.

How to cite this paper: Dramane, S., Amadou, O., Baptiste, O.A.J., Siaka, K., Constant, A., Emile, A.-K., Justin, N.K., Wilson, N.N.A., Djeinabou, D., d'Arc, L.-K.M.J. and Mathieu, C.B. (2015) Duodenal Metastases of Malignant Melanoma: One Case Report. Open Journal of Gastroenterology, 5, 111-114. http://dx.doi.org/10.4236/ojgas.2015.58018 
terized by a high malignant potential and high frequency of metastases headquartered variable [1]. Gastric and duodenal metastases of malignant melanoma are rare and account for $5 \%$ - 7\% of patients [2].

We report a case whose diagnosis could be established in pre-mortem.

\section{Case Report}

This is a woman of 86 years, hypertensive known tumor without history, who was hospitalized in March 2008 in the service of Rennes University Hospital Liver Diseases for an impaired general condition and without iron deficiency anemia home externalizing found. The symptoms date back to one year, by the occurrence of a progressively increasing dyspnea on exertion, accompanied by dizziness, anorexia and asthenia; all operating in a significant progressive slimming context. For two months before her hospitalization, appeared abdominal pain epigastric seat without digestive disorders.

Many treatments (anti secretory and anti-anemic) were administered without success. On physical examination, it was objectified anemic syndrome, with firm skin nodules of about $2 \mathrm{~cm}$ in diameter, located in the chest, abdomen, limbs and the lower lip. We have not found nevus on the skin. Moreover, we noted the presence of axillary lymphadenopathy painless left about $3 \mathrm{~cm}$ in diameter. There was no melena on rectal examination. Biology had found a hemoglobin level of $5.2 \mathrm{~g} / \mathrm{dl}$ hypochromic microcytic (MCV = $69 \mathrm{fl}$ ), a normal leukocyte levels in $7235 / \mathrm{mm}^{3}$ et normal platelets to $158,000 / \mathrm{mm}^{3}$ (Table 1). Gastroscopy was highlighted, of ulcerative budding polypoid lesions with blackish pigmentation in places at the bulb and the second duodenum (Figure 1) that were biopsied, there was no injury to the esophagus and stomach. Histologically, there was a tumor proliferation made of rounded cells and sometimes fusiform cuboid carrying cellular massive fairly large. These cells showed atypia with irregular melanin rich cores (Figure 2). Immunohistochemistry showed positivity of these tumor cells to anti-S100 protein antibodies and anti HMB45 and concluded the diagnosis of duodenal metastasis of malignant melanoma. The thoraco-abdominopelvic CT scan objectifying a voluminous mass of $6 \mathrm{~cm}$ in contact with the duodenum and the left hepatic lobe and extending to the abdominal wall. Multiple bilateral pulmonary nodules of metastatic pace, mediastinal lymphadenopathy (latero-tracheal left and in front of the descending aorta) and multiple peritoneal and retro peritoneal nodules associated with many lymph nodes were also

\section{Table 1. Laboratory tests.}

Microcytic hypochromic anemia: hemoglobin rate $=5.2 \mathrm{~g} / \mathrm{dl}, \mathrm{VGM}=69 \mathrm{fl}$

Leukocytes: normal $=7235 / \mathrm{mm}^{3}$

Platelets: normal $=158000 / \mathrm{mm}^{3}$

CRP: high $=44 \mathrm{mg} / \mathrm{l}$

Transaminases: normal

Bilirubin total and conjugated: normal

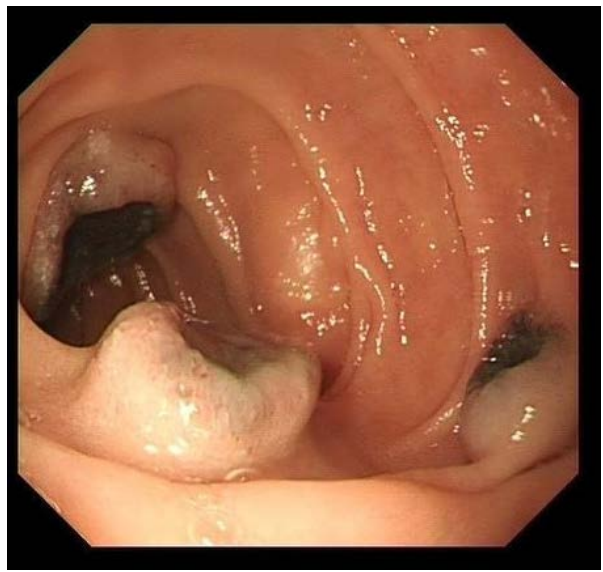

Figure 1. Polypoid lesion ulcerative budding with a blackish pigmentation. 


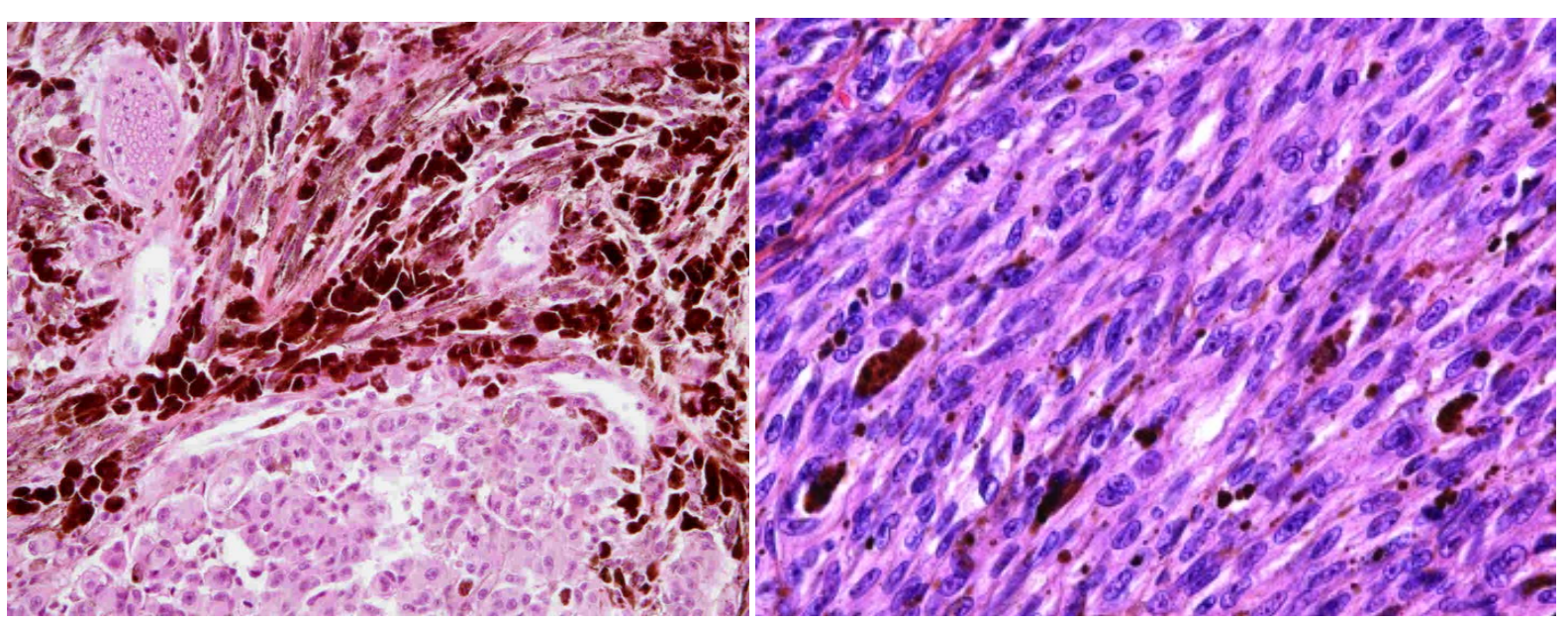

Figure 2. Mixed melanoma cells (fusiform and epithelioid).

found. The patient received symptomatic treatment with PRBC transfusion base, anti-anemic, anti-secretory and analgesic. The trend was stable and allowed the return home of the patient. The death occurred two months later in an array of cardiovascular collapse due to upper gastrointestinal bleeding in great abundance.

\section{Discussion}

Malignant melanoma is a rare tumor and its prevalence is increasing in the US where it represents $1 \%-3 \%$ of all cancers [2], it primarily affects the skin and mucous membranes. This tumor is characterized by a high malignant potential and high frequency of metastases headquartered variable [1]. The diagnosis of digestive metastases of malignant melanoma living subject is performed in $5 \%-7 \%$ of cases, while the autopsy of deceased patients, found $60 \%$ of cases [3]. These digestive maps serve more often in the mesentery or distal small intestine as the proximal part of the gastrointestinal tract [4]. The stomach and duodenum are less often involved [5] [6]. Frequency distribution of metastases in the digestive tract level is: $4 \%$ esophagus, stomach $26 \%, 12 \%$ duodenum, small intestine 58\%, 22\% colon, rectum 5\%. Preferential duodenal metastatic sites are the peri-ampullary region and bulb [7] [8].

It is a highly malignant and aggressive tumor, occurring most often in adults after 50 years, regardless of sex. In etiopathogenic level, risk factors have been implicated such as exposure to sunlight [9], but especially the existence of a particular skin lesion predisposing primitive acquired melanosis and cutaneous nevi. In our patient, the subcutaneous nodules disseminated non-pigmented, not allowed to suspect the diagnosis. Clinical diagnosis is often easy, in front of a well-known story of the primary tumor, but can long remain unknown and responsible for metastasis.

In most published studies, the diagnosis of melanoma foregoing averaging 4 years the appearance of nonspecific gastrointestinal symptoms including nausea, vomiting, abdominal pain, gastrointestinal bleeding, weight loss and anemia [7] [8] as is the case in our observation. Endoscopy is the examination of the diagnostic and therapeutic resource sometimes when surgery (standard treatment) is impossible. The development of modern noninvasive imaging makes it easier to detect gastrointestinal metastases. Tomography of the abdomen shows the contrast with subcutaneous nodules and a nodule near the bulb compatible gastroscopy, plus multiple bilateral pulmonary nodules liver, demonstrating the bilateral adrenal metastatic origin.

A histological examination, malignant melanoma is characterized by the mean tumor thickness of patients who underwent surgical resection of $2.5 \mathrm{~mm}$, with a range of 0.5 to $7 \mathrm{~mm}$. The tumor thickness is a prognostic factor for recurrence and metastasis as demonstrated by the data in the literature [10] [11]. According to Breslow classification, tumors with a thickness $\geq 2 \mathrm{~mm}$ have a poor prognosis, promoting recurrence [10] [11].

The variant epithelioid cells, is recognized as a poor prognosis with a mortality rate three times [10] [11].

\section{Conclusion}

The increasing incidence of malignant melanoma fears of a proportional increase of digestive metastases and 
encourages detect as early as possible. It is always necessary to seek digestive localizations to the signs of gastrointestinal call or as part of an iron deficiency anemia.

\section{References}

[1] Lee, E.Y., Heiken, J.P. and Huettner, P.C. (2003) Late Recurrence of Malignant Melanoma Presenting as Peritoneal “Carcinomatosis”. Abdominal Imaging, 28, 284-286. http://dx.doi.org/10.1007/s00261-002-0039-X

[2] McDermott, V.G., Low, V.H., Keogan, M.T., et al. (1996) Malignant Melanoma Metastatic to the Gastrointestinal Tract. American Journal of Roentgenology, 4, 809-813. http://dx.doi.org/10.2214/ajr.166.4.8610555

[3] Liang, K.V., Sanderson, S.O., Nowakowski, G.S., et al. (2006) Metastatic Malignant Melanoma of the Gastrointestinal Tract. Mayo Clinic Proceedings, 81, 511-516. http://dx.doi.org/10.4065/81.4.511

[4] Telerman, A., Gérard, B., Van der Heule, B., et al. (1985) Gastrointestinal Metastasis from Extra Abdominal Tumor. Endoscopy, 17, 99-101. http://dx.doi.org/10.1055/s-2007-1018470

[5] Oda, H.K., Yamao, T.S., Ono, H.G., et al. (2001) Metastatic Tumor to the Stomach: Analysis of 54 Patients Diagnosed at Endoscopy and 347 Autopsy Cases. Endoscopy, 33, 507-510. http://dx.doi.org/10.1055/s-2001-14960

[6] Marin, M., Vlad, L., Grigorecu, M., et al. (2002) Metastasis of Malignant Melanoma in the Small Intestine: A Case Report. Romanian Journal of Gastroenterology, 11, 53-56.

[7] Michelassi, F. (1989) Experience with 647 Consecutive Tumors of the Duodenum, Ampulla, Head of the Pancreas and Distal Common Bile Duct. Annals of Surgery, 210, 554-556. http://dx.doi.org/10.1097/00000658-198910000-00015

[8] Geboes, K., de Jaeger, E., Rutgeerts, P., et al. (1988) Symptomatic Gastrointestinal Metastases from Malignant Melanoma: A Clinical Study. Journal of Clinical Gastroenterology, 10, 64-70. http://dx.doi.org/10.1097/00004836-198802000-00014

[9] Slingluff, C.L., Flaherty, K., Rosenberg, S.A. and Read, P.W. (2011) Cutaneous Melanoma. In: DeVita, V.T., Lawrence, T.S. and Rosenberg, S.A., Eds., DeVita, Hellman, and Rosenberg's Cancer: Principles \& Practice of Oncology, 9th Edition, Lippincott Williams and Wilkins, Philadelphie, 1643-1691.

[10] Breslow, A. (1970) Thickness, Cross-Sectional Areas and Depth of Invasion in the Prognosis of Cutaneous Melanoma. Annals of Surgery, 172, 902-908. http://dx.doi.org/10.1097/00000658-197011000-00017

[11] Chakera, A.H., Hesse, B., Burak, Z., et al. (2009) EANM-EORTC General Recommendations for Sentinel Node Diagnostics in Melanoma. European Journal of Nuclear Medicine and Molecular Imaging, 36, 1713-1742. http://dx.doi.org/10.1007/s00259-009-1228-4 